\title{
OPEN Publisher Correction: Integrated photonic guided metalens based on a pseudo-graded index distribution
}

\section{Karim Hassan (D), Jacques-Alexandre Dallery, Pierre Brianceau \& Salim Boutami}

Correction to: Scientific Reports https://doi.org/10.1038/s41598-020-58029-z, published online 24 January 2020

This Article contains an error in Equation 5.

$\widetilde{\mathrm{n}}_{\text {eff-TM-EMT }}^{2}(f)=f \cdot n_{\text {slab-TM }}^{2}+(1-f) \varepsilon_{g}+\frac{1}{3}\left[\frac{P}{\lambda}, \pi, f,(, 1,-, f,),\left(, n_{\text {slab }-T M}^{2},-\varepsilon_{g},\right)\right]^{2}$

should read:

$\widetilde{\mathrm{n}}_{\text {eff-TM-EMT }}^{2}(f)=f \cdot n_{\text {slab-TM }}^{2}+(1-f) \varepsilon_{g}+\frac{1}{3}\left[\frac{P}{\lambda} \pi f(1-f)\left(n_{\text {slab-TM }}^{2}-\varepsilon_{g}\right)\right]^{2}$

In addition, this Article contains an error in the Methods.

"The electron-beam lithography process (VISTEC variable-shape VB6B) was optimized using $85 \mathrm{~nm}$ of negative tone resist from TOK (OEBR-CAN038) on top of $30 \mathrm{~nm}$ of silicon antireflective coating (SiARC) ISX412 and $130 \mathrm{~nm}$ of spin on carbon (SOC) HM8102."

should read:

"The electron-beam lithography process (VISTEC variable-shape SB3054) was optimized using $85 \mathrm{~nm}$ of negative tone resist from TOK (OEBR-CAN038) on top of $30 \mathrm{~nm}$ of silicon antireflective coating (SiARC) ISX412 and $130 \mathrm{~nm}$ of spin on carbon (SOC) HM8102."

(c) Open Access This article is licensed under a Creative Commons Attribution 4.0 International License, which permits use, sharing, adaptation, distribution and reproduction in any medium or format, as long as you give appropriate credit to the original author(s) and the source, provide a link to the Creative Commons license, and indicate if changes were made. The images or other third party material in this article are included in the article's Creative Commons license, unless indicated otherwise in a credit line to the material. If material is not included in the article's Creative Commons license and your intended use is not permitted by statutory regulation or exceeds the permitted use, you will need to obtain permission directly from the copyright holder. To view a copy of this license, visit http://creativecommons.org/licenses/by/4.0/.

(c) The Author(s) 2020 